\title{
Dietary phosphatidylcholine affects postprandial plasma levels and digestibility of lipid in common carp (Cyprinus carpio)
}

\author{
Inge Geurden*, Sadasivam Kaushik and Geneviève Corraze \\ INRA, UMR1067 Nutrition, Aquaculture and Genomics, NuAGe, INRA Hydrobiology Station, Saint Pée-sur-Nivelle F-64310, \\ France
}

(Received 28 September 2007 - Revised 30 November 2007 - Accepted 3 December 2007 - First published online 9 May 2008)

This study examined the effect of purified soyabean phosphatidylcholine (SPC) on circulating plasma lipids and nutrient digestibility in juvenile common carp. The fish (100 (SD 15) g, $25^{\circ} \mathrm{C}$ ) were fed, for 4 weeks, a casein-based diet containing either $12 \%$ soyabean oil (diet SBO) or $8 \%$ SBO plus $4 \%$ SPC (diet SPC). The lipid, protein and energy contents of the faeces were analysed for the determination of apparent digestibility. At the end of the trial, the fish were fasted for $48 \mathrm{~h}$ and fed a single meal. Plasma lipids were then analysed over the next $48 \mathrm{~h}$. The growth $(1.63 v .1 .26 \%$ per d) and apparent lipid digestibility $(96.3$ v. $92.1 \%)$ were higher in SPC- than in SBO-fed fish. The amplitude of the postprandial $(8 \mathrm{~h}$ after the meal) TAG peak was identical in fish from both treatments, despite the $33 \%$ lower amount of TAG in diet SPC. Both observations support the idea that SPC stimulates intestinal TAG uptakes. The lower TAG:phospholipid ratio of the secreted plasma lipids at the time of absorption suggests a larger number of smaller intestinal lipoproteins in SPC- than SBO-fed fish, possibly due to the recycling of absorbed lysophosphatidylcholine for chylomicron formation. In the $48 \mathrm{~h}$ unfed state, phospholipid levels remained approximately $20 \%$ higher in SPC-fed than in SBO-fed fish, but we observed no hypocholesterolaemic effect of SPC. In summary, the present data support earlier histological indications of a positive role of dietary phosphatidylcholine in intestinal TAG uptakes in carp.

Lecithin: Dietary phospholipids: Intestinal lipid absorption: Circulating plasma lipids: Teleost fish

The observation in higher vertebrates that the presence of luminal phospholipids (PL) enhances intestinal TAG uptakes $^{(1-6)}$ has led to the formulation of several hypotheses. For instance, the oral administration of lecithin to weanling pigs has been suggested to play a role in the emulsification of dietary fat in the lumen and hence to facilitate the uptake of fat by the intestinal cell ${ }^{(7)}$. Dietary PL may furthermore enhance the export of lipid out of the cell into circulation since hydrolysed lyso PL, once taken up by the enterocyte, can be re-acylated and used for formation of the polar lipid coat of intestinal lipoproteins ${ }^{(3,8)}$. In addition, luminal PL have been reported to regulate the synthesis of apolipoproteins, crucial for the assembly of intestinal lipoproteins, as seen in vivo for apo A-I in newborn pig enterocytes ${ }^{(9)}$ and in vitro for apo B-48 in intestinal $\mathrm{CaCo}-2$ cell lines ${ }^{(10)}$. Interestingly, the latter study showed that the increased apo B-48 synthesis, accompanied by increased TAG secretion, was more pronounced following co-incubation with phosphatidylcholine (PC) than with other PL classes ${ }^{(10)}$, indicating a specific effect of PC on intracellular lipid mobilization. Besides their effect on lipid absorption, PL administrations have also been found to affect further lipoprotein metabolism, hepatic lipid processing and to augment the biliary lipid flow, inducing alterations in the plasma lipid profile, such as lowered cholesterol ${ }^{(11-14)}$.
In lower vertebrates, little is known on the effect of dietary PL on circulating or postprandial plasma lipid levels. By contrast, a large number of studies have demonstrated the beneficial effects of dietary PL on growth and digestibility in juvenile and adult teleost fish ${ }^{(15-18)}$. Furthermore, at the larval stage, fish even seem to have a dietary requirement for PL in order to obtain good survival and growth during early development ${ }^{(19-21)}$ with a different response according to the supplied PL class ${ }^{(22)}$. In trials with first-feeding common carp larvae, PC exerted the strongest growth-promoting effect, whereas phosphatidylinositol improved survival and reduced the occurrence of larval deformities ${ }^{(23,24)}$. That PC, as outlined earlier for mammals, also plays an active role in the absorption of dietary neutral lipid was evidenced by histological examination of intestines from 25-d-old carp sampled from the latter two studies. The results showed important lipid droplet accumulations in enterocytes of PC-devoid or phosphatidylinositol-fed fish, which were completely absent when fed a dietary PC source ${ }^{(25)}$. This finding is thus consistent with reports in mammals that not the entry or re-esterification of the lipids in the cell, but the ability of the enterocyte to export TAG is impaired in the absence of dietary $\mathrm{PC}^{(3,4,10)}$. Similar conclusions were made following the observation of lipid droplets in the enterocytes of two species of adult salmonids fed PC-free diets ${ }^{(26,27)}$. 
Other indications of the stimulating effect of dietary PL on intestinal lipid mobilization concern the increased recovery of essential fatty acids (DHA and EPA) and of radiolabelled oleic acid in body lipids of marine fish fed $\mathrm{PC}^{(28,29)}$. Taken the afore-mentioned findings together, it would hence not be surprising to find an effect of a dietary PL supply, particularly of PC, on circulating and postprandial plasma lipids in fish.

The present study examined to what extent dietary PC affects the postprandial and circulating lipids in the plasma of juvenile common carp fed a semi-purified casein-based diet containing purified soyabean PC compared with an isolipidic diet without PC. We also analysed the lipid levels in the faeces of fish from both treatments in order to estimate the amount of fat absorbed when fed a diet with or without PC.

\section{Experimental methods}

\section{Experimental animals and diets}

Common carp (Cyprinus carpio) juveniles of 100 (SD 15) g initial body weight were placed in 60-litre cylindroconical tanks (fourteen fish per tank). The outlet of each tank of the recirculating system was equipped with a continuous filtering device for collecting the faeces ${ }^{(30)}$. The water temperature was maintained at $25^{\circ} \mathrm{C}$ and the photoperiod was $12-12 \mathrm{~h}$ light-dark. Each diet was fed twice per $d$ to visual satiation for 4 weeks to quadruplicate groups. The two semi-purified diets were based on casein and gelatine as a protein source and differed only by their lipid composition (Table 1). Diet SBO contained $12 \%$ soyabean oil (Lesieur, France) and diet SPC contained $8 \%$ soyabean oil and $4 \%$ purified soyabean PC (95\% PC; Epikuron 200, Lucas Meyer GmbH, Germany). The vitamin mix supplied both diets with $2000 \mathrm{mg} / \mathrm{kg}$ choline chloride (60\% choline), fulfilling the choline requirement for carp ${ }^{(31)}$. Chromic oxide $\left(\mathrm{Cr}_{2} \mathrm{O}_{3}, 1 \%\right)$ was added as an indigestible marker.

\section{Growth and apparent digestibility}

The fish from each tank (four tanks per diet) were bulk-weighed and counted at the end of the trial in order to calculate the

Table 1. Formulation and proximate composition of the semi-purified isolipidic diets containing soyabean oil (diet SBO) or soyabean oil plus soyabean phosphatidylcholine (diet SPC) fed to juvenile common carp for 4 weeks ${ }^{\star}$

\begin{tabular}{lcc}
\hline & Diet SBO & Diet SPC \\
\hline Ingredients (g/100 g diet) & 12 & 8 \\
$\quad$ Soyabean oil & - & 4 \\
Soyabean phosphatidylcholine & 87 & 87 \\
Common basis & 1 & 1 \\
$\mathrm{Cr}_{2} \mathrm{O}_{3}$ & & \\
Analysed composition & 89.5 & 91.0 \\
DM (\%) & 12.3 & 12.2 \\
Lipid (\% DM) & 44.7 & 45.0 \\
Protein (\% DM) & $10 \cdot 1$ & 10.2 \\
Ash (\% DM) & 21.3 & 21.0 \\
Gross energy (kJ/g DM) & & \\
\hline
\end{tabular}

* For details of diets and procedures, see Experimental methods.

† Modified from Guelph purified salmonid diet ${ }^{(31)}$. Composition (\% diet): casein 40; gelatine 4; DL-methionine 0.5 ; L-arginine 1 ; starch 10.5 ; dextrin 8 ; D-glucose 5 ; $\alpha$-cellulose 5 ; celite 1 ; sodium-alginate 1 ; vitamin mix 3; mineral mix 8 . final body weight $(\mathrm{BW})$ and specific growth rate $(\% / \mathrm{d})=100 \times$ $\left(\ln \left(\mathrm{BW}_{\text {final }}{ }^{1 / 3}\right)-\ln \left(\mathrm{BW}_{\text {initial }^{1 / 3}}\right)\right) /$ days of trial duration. The faeces were collected daily from each tank (four tanks per diet) during the last 2 weeks of the feeding period and frozen at $-20^{\circ} \mathrm{C}$. They were freeze-dried and pooled per tank prior to analysis. Diets and faeces were analysed for DM $\left(105^{\circ} \mathrm{C}\right.$ for $24 \mathrm{~h})$, ash $\left(550^{\circ} \mathrm{C}\right.$ for $\left.12 \mathrm{~h}\right)$, lipid (Soxtherm, Gerhardt), protein $(\mathrm{N} \times 6.25$, Kjeldahl Nitrogen analyser 2000; Fison Instruments), gross energy (adiabatic bomb calorimetry, IKA) and chromic oxide (perchloric acid digestion, according to Bolin and colleagues $\left.{ }^{(32)}\right)$. The apparent digestibility coefficients (ADC) were calculated using the formula:

$$
\operatorname{ADC}(\%)=100-\left(100 \times\left(\mathrm{Cr}_{2} \mathrm{O}_{3} \text { diet } / \mathrm{Cr}_{2} \mathrm{O}_{3} \text { faeces }\right) \times\right.
$$

(nutrient faeces/nutrient diet)).

\section{Circulating and postprandial plasma lipids}

After the 4-week feeding period, the fish were starved for $48 \mathrm{~h}$ in order to have the basal levels of plasma lipids and fed a single meal to satiation. Five individuals from each dietary treatment were taken randomly at $4,6,8,10,12,16,24,30$ and $48 \mathrm{~h}$ after the meal for blood sampling from the caudal vein. Sampled fish were placed in a separate tank in order to avoid sampling the same fish twice. Plasma was separated from whole blood (plus $0.01 \%$ heparin) in situ by centrifugation $(1500 \mathrm{~g}, 5 \mathrm{~min})$ and was frozen at $-80^{\circ} \mathrm{C}$ until subsequent analyses. The lipid composition of the plasma was analysed using enzymatic procedures, commercialized by Biomérieux (France) for PL, TAG and total cholesterol (free and esterified) and by Wako Chemicals (Germany) for NEFA.

\section{Statistical analyses}

The final body weight (log-transformed) and specific growth rate of the fish were subjected to a one-way analysis of covariance using the initial body weight (log-transformed) as a covariate. The apparent digestibility coefficients (asin-transformed) were analysed by a one-way ANOVA. The effects of diet and sampling time on plasma lipid levels were analysed by a two-way ANOVA, followed by one-way ANOVA in case of a significant interaction. Significant differences between means were evaluated by the Newman-Keuls test. The significance level was set at $P<0 \cdot 05$. The analyses were performed using the STATISTICA software program (Statsoft Inc., Tulsa, OK, USA).

\section{Results \\ Growth}

The survival of the carp during the 4-week feeding trial was $100 \%$ in both dietary treatments. The SPC-fed fish had a significantly higher final body weight and specific growth rate than fish fed the SBO diet (Table 2).

\section{Apparent digestibility}

There was a significant increase in the apparent digestibility of total lipid $(P=0.0007$, Table 2$)$ when the carp were fed the 
Table 2. Body weight (BW), specific growth rate (SGR) and apparent digestibility coefficients of dietary components in common carp fed the experimental diets for 4 weeks ${ }^{*}$

(Values are means and standard deviations for four tanks per diet)

\begin{tabular}{|c|c|c|c|c|c|}
\hline & \multicolumn{2}{|c|}{ Diet SBO } & \multicolumn{2}{|c|}{ Diet SPC } & \multirow[b]{2}{*}{$P$ value $\dagger$} \\
\hline & Mean & SD & Mean & SD & \\
\hline Initial BW (g) & 101 & 16 & 106 & 17 & 0.673 \\
\hline Final BW (g) & 140 & 14 & 164 & 18 & 0.003 \\
\hline SGR (\% per d) & $1 \cdot 26$ & 0.32 & 1.63 & 0.21 & 0.003 \\
\hline \multicolumn{6}{|c|}{ Apparent digestibility coefficients (\%) } \\
\hline Lipid & $92 \cdot 1$ & 0.5 & $96 \cdot 3$ & 0.7 & $<0.001$ \\
\hline Protein & $96 \cdot 6$ & 0.3 & $96 \cdot 9$ & 0.3 & 0.482 \\
\hline Gross energy & 89.2 & $0 \cdot 1$ & $90 \cdot 2$ & 0.4 & 0.011 \\
\hline
\end{tabular}

Diet SBO, soyabean oil; Diet SPC, soyabean oil plus soyabean phosphatidylcholine.

${ }^{*}$ For details of diets and procedures, see Experimental methods.

†ANOVA (except for final BW and SGR for which an analysis of covariance was used with initial BW as covariate).

diet supplemented with soyabean PC $(96 \cdot 3 \%)$ as compared with the PC-free diet SBO $(92 \cdot 1 \%)$. The positive effect of a $\mathrm{PC}$ addition was also seen for the apparent digestibility of energy, which was found to be slightly but significantly $(P=0 \cdot 011)$ higher in the SPC than SBO groups. The apparent protein digestibility was elevated and did not differ between both treatments (Table 2).

\section{Circulating baseline and postprandial plasma lipids}

Following the $48 \mathrm{~h}$ fast, the plasma baseline levels (Fig. 1) comprised between 175 and $200 \mathrm{mg} / \mathrm{dl}$ for TAG, 130 and
$140 \mathrm{mg} / 100 \mathrm{ml}$ for total (free and esterified) cholesterol and between 12 and $16 \mathrm{mg} / 100 \mathrm{ml}$ for NEFA. The latter baseline concentrations were unaffected by the dietary treatment $(P>0.05)$. The plasma PL level following the $48 \mathrm{~h}$ fast (Fig. 1 (b)) was almost $20 \%$ higher $(P=0 \cdot 010)$ in the SPCfed fish $(500 \mathrm{mg} / 100 \mathrm{ml})$ than in the SBO-fed fish $(420 \mathrm{mg} /$ $100 \mathrm{ml})$. The resulting core-to-surface TAG:PL ratio of the plasma lipids in the $48 \mathrm{~h}$ unfed fish were significantly lower $(P=0.023)$ in fish from the SPC than from the SBO treatment ( 0.35 and 0.47 , respectively).

Feeding a single meal led to a rapid rise in the concentration of plasma TAG (Fig. 1 (a)). This increase was apparent $4 \mathrm{~h}$
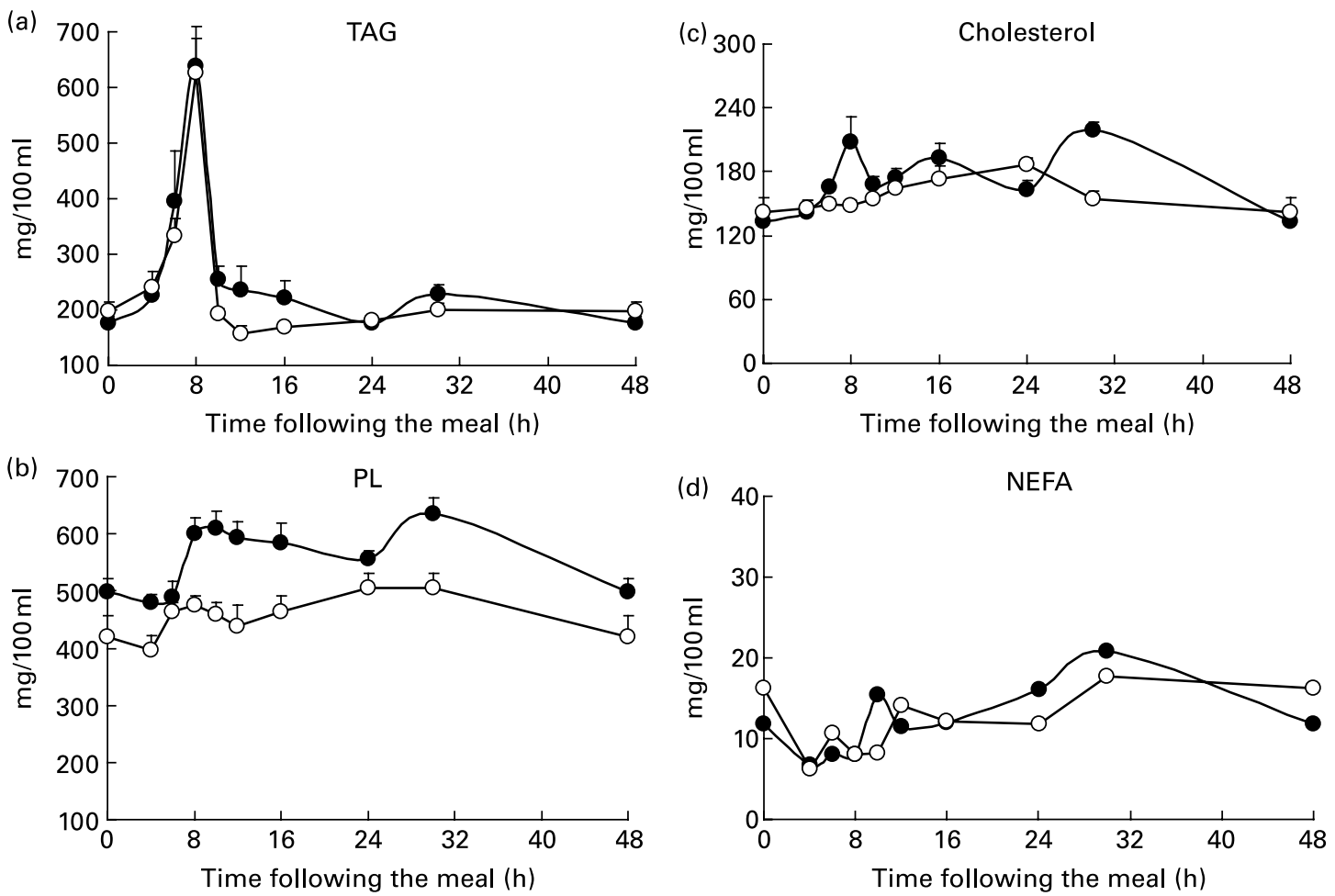

Fig. 1. Changes in circulating plasma lipids in juvenile carp during the $48 \mathrm{~h}$ following the administration of a single isolipidic meal with (diet SPC, $-\mathbf{-}$ ) or without (diet SBO, -O-) soyabean phosphatidylcholine (PC). (a) TAG; (b) phospholipids (PL); (c) cholesterol; (d) NEFA. Values are means with their standard errors of the mean from five fish per sampling point. Statistical differences in postprandial plasma lipid profiles related to the dietary treatment and sampling time are shown in Results. For details of diets and procedures, see Experimental methods. 
after the meal as shown by the 20 to $30 \%$ increase relative to the baseline TAG level. After the meal $(6 \mathrm{~h})$, the relative TAG increases were 168 and $225 \%$ in SBO-fed and SPC-fed fish, respectively. The TAG absorption peak reached its apparent maximum $8 \mathrm{~h}$ after the meal showing a more than 3-fold (365\%) increase relative to baseline level This corresponds with a net increase (peak minus baseline level) of 430 and $460 \mathrm{mg}$ per $100 \mathrm{ml}$ in fish fed diets SBO and SPC, respectively. During the next $2 \mathrm{~h}$, there was a rapid drop in TAG, with levels at $10 \mathrm{~h}$ resembling baseline levels (Fig. 1 (a)). The two-way ANOVA performed on plasma TAG indicated a significant effect of time after meal $(P<0.0001 ;$ T8 $>$ T6 $>$ $\mathrm{T} 4=\mathrm{T} 10=\mathrm{T} 12=\mathrm{T} 16=\mathrm{T} 24=\mathrm{T} 32=\mathrm{T} 48)$, but not of the $\operatorname{diet}(P=0 \cdot 12)$. The interaction term (diet $\times$ time) was not significant $(P=0 \cdot 85)$.

Following the meal, the plasma PL levels first showed a slight $(5 \%)$ decrease (at $4 \mathrm{~h})$, whereafter they increased up to $475 \mathrm{mg}$ (SBO-fed fish, at $8 \mathrm{~h}$ ) and $600 \mathrm{mg}$ per $100 \mathrm{ml}$ (SPC-fed fish, at $8-10 \mathrm{~h}$ ), which represents a 12 and $20 \%$ increase as compared with the respective baseline levels (Fig. 1 (b)). The net increase in plasma PL (peak minus baseline level) was $55 \mathrm{mg}$ per $100 \mathrm{ml}$ with diet SBO and $98 \mathrm{mg}$ per $100 \mathrm{ml}$ with diet SPC. In both treatments, the postprandial peak was followed by a second peak seen $30 \mathrm{~h}$ after the meal, which was less sharp but with slightly higher amplitude (Fig. 1 (b)). The two-way ANOVA performed on plasma PL showed a highly significant effect of the diet $(P<0.0001$; SPC $>$ SBO $)$ and of sampling time $(P=0.0001 ; \mathrm{T} 30=\mathrm{T} 24=$ $\mathrm{T} 10=\mathrm{T} 8=\mathrm{T} 12=\mathrm{T} 16>\mathrm{T} 6=\mathrm{T} 48>\mathrm{T} 4)$, without interaction (diet $\times$ time, $P=0 \cdot 26$ ).

At the moment of the postprandial TAG peak (at $8 \mathrm{~h}$ ), the TAG:PL ratio of the total plasma lipids was 1.06 and 1.31 in SPC- and SBO-fed fish, respectively $(P=0 \cdot 13$, one-way ANOVA). In order to compare the plasma TAG:PL ratios of the lipids, which had entered the circulation during absorption in fish from both treatments, we used the net increases (peak minus baseline values) of TAG and PL. These ratios were significantly affected by the diet ( $P=0.004$, one-way ANOVA), being 7.8 in SBO-fed fish and only 4.6 in SPC-fed fish.

Postprandial fluctuations in cholesterolaemia (Fig. 1 (c)) observed at the different sampling times did not fully coincide in both treatments as indicated by the significant interaction term diet $\times$ time (two-way ANOVA, $\mathrm{F}_{8,72} 4 \cdot 25, P=0.0003$ ). For instance, a small peak occurred at $8 \mathrm{~h}$ in SPC-fed fish, which was absent in SBO-fed fish, and the second peak at $30 \mathrm{~h}$ in SPC-fed might correspond with the peak seen at $24 \mathrm{~h}$ in SBO-fed fish $(P<0 \cdot 05$, one-way ANOVA). The dietary effect was only significant at two sampling points (at $8 \mathrm{~h}, P=0.013$ and at $30 \mathrm{~h}, P=0.002)$ indicating higher cholesterol in SPCthan SBO-fed fish (one-way ANOVA). As mentioned earlier, no differences in cholesterol levels were noted at $48 \mathrm{~h}(P=0.63)$.

Postprandial plasma NEFA levels were low (Fig. 1 (d)). As for cholesterol, there was a significant interaction between diet $\times$ sampling time (two-way ANOVA, $\mathrm{F}_{8,72} \quad 7 \cdot 33$, $P<0.0001)$. We noted a slight increase in NEFA at $10 \mathrm{~h}$ in SPC-fed fish, seen $2 \mathrm{~h}$ later in SBO-fed fish. In both treatments, however, the highest NEFA levels were seen at $30 \mathrm{~h}$ and lowest levels at $4 \mathrm{~h} \quad(P<0 \cdot 05$, one-way ANOVA). At none of the sampling times did we find a dietary effect on circulating NEFA ( $P>0.05$, one-way ANOVA).

\section{Discussion}

The observation that plasma NEFA did not significantly increase following the meal confirms early studies in teleost fish that fatty acids released in the lumen and taken up by the enterocytes are being re-esterified prior to their entry into the circulatory system ${ }^{(33-35)}$. More recent studies showed that the synthesis and re-acylation pathways of TAG and PL in teleost enterocytes do not differ substantially from those in mammals ${ }^{(36,37)}$. In the present study, the postprandial rise in TAG was already apparent after $4 \mathrm{~h}$ and reached its maximum after $8 \mathrm{~h}$, which is more than twice as fast as in an earlier study with carp, where the TAG peak appeared only after $20 \mathrm{~h}^{(35)}$. This difference is most probably caused by the higher temperature in the present study, known to accelerate lipid absorption in fish ${ }^{(38)}$. Except for the modestly higher plasma TAG at $6 \mathrm{~h}$ in SPC- than SBO-fed fish, there was no noticeable acceleration of lipid absorption due to dietary SPC, in contrast with what could be expected from studies with bile-diverted rat $^{(2)}$ or mice ${ }^{(39)}$. Exogenous PC administration to latter rodents without biliary PL in the intestinal lumen strongly enhanced the rate of appearance of plasma $\mathrm{TAG}^{(2,39)}$ and some of this earlier work concluded that the availability of luminal lecithin is a requisite for intestinal lipid absorption ${ }^{(1,3)}$. Moreover, studies conducted with rat under normal physiological conditions showed that exogenous PL administration (in addition to the normal bile supply) resulted in a more efficient net uptake of the dietary lipid ${ }^{(5,6)}$. Our data are consistent with the latter observations as: (i) the apparent lipid digestibility was improved in the SPC-fed carp; (ii) the maximum concentration of the postprandial TAG peak was identical in fish from both dietary treatments, despite the $33 \%$ lower TAG level in the SPC than in SBO diet as well as the $33 \%$ lower amount of fatty acids provided by soya PC than by soya oil. Some studies in fish ${ }^{(15,17)}$ or young pigs ${ }^{(7)}$ have attributed the improved lipid digestibility to the emulsifying properties of PL, enhancing the luminal fat digestion and uptake of micelles through the unstirred water layer and thus the entry into the cell. There is, however, ample evidence from mammalian studies that it is not the uptake of the lipolytic products by the cell, but the export from the cell that is impaired in cases of PL-deficiency ${ }^{(3,4,10)}$. This was also suggested in fish $^{(26,27)}$, in line with our earlier histological observations of large lipid droplet accumulations in enterocytes of larval carp fed a diet devoid of $\mathrm{PC}^{(25)}$. Importantly, these droplets, regarded as a form of temporary TAG storage when the entry of fatty acids in the cell exceeds the output capacity ${ }^{(34,26)}$, were not seen in carp larvae fed dietary $\mathrm{PC}^{(25)}$. Further, larvae fed the PC-supplemented diets showed improved growth and survival compared with larvae fed the PC-free diet ${ }^{(23,24)}$. The present study confirms the growth-promoting effect of PC, although to a lesser extent than in firstfeeding carp larvae.

The intracellular mechanisms by which luminal PL stimulate intestinal lipid export are not fully understood. In vitro studies with Caco-2 cells demonstrated an enhancing effect of PC on chylomicron synthesis and assembly by triggering the synthesis of specific apolipoproteins, such as apo $\mathrm{B} 48^{(10)}$. Alternatively, chylomicron formation can also be enhanced by an increased availability of polar lipid surface material. As such, the hydrolysed, absorbed and re-acylated 
sn-1 lysoPC may be directly used for intestinal chylomicron formation. In carp, however, some controversy exists regarding the intestinal lipoproteins involved in the absorption process. Iijima et al. ${ }^{(35)}$ suggested an important role for HDL since the majority of the radioactivity of orally administered fatty acids appeared first in HDL instead of chylomicrons or VLDL. This is in disagreement with earlier electron microscopic observations in carp, which revealed the presence of VLDL-like particles in the absorbing enterocytes ${ }^{(40)}$ or with studies in other teleosts showing large chylomicrons and VLDL-like lipoproteins during lipid absorption ${ }^{(34,41)}$. In the present study, it is believed that the carp secreted VLDL or chylomicra rather than HDL during the absorption process since the TAG:PL ratio $(>4.5)$ of the lipids that had entered circulation at the time of the absorption peak (peak minus baseline values) is too elevated for HDL, whose TAG:PL ratio, found to be 0.25 in carp $^{(42)}$, does not seem to exceed 0.6 in most other teleosts ${ }^{(43-45)}$. The present study also shows that the TAG:PL core-to-surface ratio of the newly secreted lipoproteins was about $70 \%$ higher in SBO- (7.8) than in SPC- (4.6) fed fish. This finding agrees with earlier reports in human subjects that lecithin ingestion promotes the production of VLDL-sized 'small chylomicrons' with a lower TAG:PL ratio than that of large chylomicrons produced after ingestion of a TAG oil ${ }^{(8)}$. Hence, the larger number of smaller chylomicrons in the SPC-fed fish, probably due to the recycling of absorbed $\mathrm{PC}$, may have promoted the export of TAG from the enterocytes into circulation. It would, however, be of interest to confirm here that the (higher) postprandial PL output in SPC-fed fish is indeed of dietary and not of biliary origin given observations in mammals that the biliary lipid output is stimulated by soyabean $\mathrm{PL}^{(12,13)}$ and that bile PC might be preferred over dietary $\mathrm{PC}$ as chylomicron PC precursor ${ }^{(46)}$. Both topics received little attention in teleosts and require further work, especially in view of the reported absence of PL in the bile of carp ${ }^{(47)}$.

In addition to its role during intestinal absorption, dietary lecithin in higher vertebrates has also been documented to affect further (intravascular and hepatic) lipoprotein and lipid metabolism, resulting in modified plasma lipid profiles ${ }^{(11-14)}$. To our knowledge, there exist no data in fish on the effect of PL on circulating plasma lipids. In the present study, the basal plasma PL level in the $48 \mathrm{~h}$ unfed fish from the SPC-treatment remained almost $20 \%$ higher than when fed the PC-free diet. This persistently higher amount of circulating PL can probably be explained by the redistribution of the PL-components of the surfaces of the (higher number of smaller) intestinal lipoproteins to the HDL fraction in the SPC-fed fish. HDL generally constitute the most abundant lipoprotein class in teleosts ${ }^{(41)}$ and in carp, which lack plasma albumin, HDL has been reported to assure the transport of non-esterified plasma fatty acids ${ }^{(48)}$ in addition to their well-documented role in cholesterol transport ${ }^{(35,42)}$. The present study, however, does not confirm the cholesterol-lowering effect of soyabean lecithin observed in mammals ${ }^{(11,13,14)}$ since the cholesterol (baseline) levels were similar in fish from both treatments. One explanation of the hypocholesterolaemic effect of lecithin in higher vertebrates is the enhanced secretion of bile lipids, particularly of bile cholesterol and bile salts, provided in increased amounts by the metabolism of plasma HDL-cholesterol whose transport to the liver is enhanced by dietary $\mathrm{PC}^{(13)}$. Further studies are needed to verify whether or why dietary PL does not seem to lower circulating cholesterol in carp, which like most other teleosts is reputed to be hypercholesterolaemic by nature ${ }^{(41)}$.

In summary, the increased lipid digestibility and the similarity in postprandial plasma TAG output in carp when replacing a part of the dietary SBO by SPC support the idea that PC stimulates the absorption of dietary lipid in fish, without further affecting the baseline level of circulating plasma cholesterol.

\section{Acknowledgements}

We thank Peyo Aguirre for his support with the digestibility trial and Marie-Jo Borthaire and Laurence Larroquet for their assistance with the biochemical analyses. No conflicts of interest are involved in this study. The study has been conducted with institutional INRA funds.

\section{References}

1. O’Doherty PJA, Kaksis G \& Kuksis A (1973) Role of luminal lecithin in intestinal fat absorption. Lipids 8, 249-255.

2. Bennett-Clark S (1978) Chylomicron composition during duodenal triglyceride and lecithin infusion. Am J Physiol Endocrinol Metab 235, E183-E190.

3. Tso P, Kendrick H, Balint JA \& Simmonds WJ (1981) Role of biliary phosphatidylcholine in the absorption and transport of dietary triolein in the rat. Gastroenterology 80, 60-65.

4. Mansbach CM II, Arnold A \& Cox MA (1985) Factors influencing triacylglycerol delivery into mesenteric lymph. Am J Physiol Gastrointest Liver Physiol 249, G642-G648.

5. Nishimukai M, Hara H \& Aoyama Y (2003) Enteral administration of soyabean lecithin enhanced lymphatic absorption of triglyceride in rats. Br J Nutr 90, 565-571.

6. Nishimukai M \& Hara H (2007) Soybean phosphatidylcholineinduced enhancement of lymphatic absorption of triglyceride depends on chylomicron formation in rats. Biosci Biotechnol Biochem 71, 1192-1197.

7. Jones D, Hancock J, Harmon D \& Walker C (1992) Effects of exogenous emulsifiers and fat sources on nutrient digestibility, serum lipids and growth performance in weanling pigs. J Anim Sci 70, 3473-3482.

8. Beil FU \& Grundy SM (1980) Studies on plasma lipoproteins during absorption of exogenous lecithin in man. $J$ Lipid Res 21, 525-536.

9. Wang H, Du J, Lu S, Sao Y, Hunter F \& Black DD (2001) Regulation of intestinal apolipoprotein A-I synthesis by dietary phosphatidylcholine in newborn swine. Lipids 36, 683-687.

10. Mathur SN, Born E, Murthy S \& Field FJ (1996) Phosphatidylcholine increases the secretion of triacylglycerol-rich lipoprotein by CaCo-2 cells. Biochem J 314, 569-575.

11. Wong EK, Nicolosi RJ \& Low PA (1980) Lecithin influence on hyperlipemia in rhesus monkeys. Lipids 15, 428-433.

12. Rioux F, Perea A, Yousef IM, Levy E, Malli L, Carrillo M \& Tuchweber B (1994) Short term feeding of diet enriched in phospholipids increase bile formation and bile acid transport maximum in rats. Biochim Biophys Acta 1214, 193-202.

13. Polichetti E, Diaconescu N, Malli L, Portugal H, Pauli AM, Tuchweber B, Yousef I \& Chanussot F (1996) Cholesterol-lowering effect of soyabean lecithin in normolipidaemic rats by stimulation of biliary lipid secretion. Br J Nutr 75, 471-481.

14. Wilson TA, Meservey CM \& Nicolosi RJ (1998) Soy lecithin reduces plasma lipoprotein cholesterol and early atherogenesis in hypercholesterolemic monkeys and hamsters: beyond linoleate. Atherosclerosis 140, 147-153. 
15. Poston HA (1991) Response of rainbow trout to soy lecithin, choline and autoclaved isolated soy protein. Prog Fish Cult 53, 85-90.

16. Craig SR \& Gatlin DM (1997) Growth and body composition of juvenile red drum (Sciaenops ocellatus) fed diets containing lecithin and supplemental choline. Aquaculture 151, 259-267.

17. Hung SSO, Berge GM \& Storebakken T (1997) Growth and digestibility of soya lecithin and choline chloride on juvenile Atlantic salmon. Aquac Nutr 3, 141-144.

18. Kasper CS \& Brown PB (2003) Growth improved in juvenile Nile tilapia fed phosphatidylcholine. $N$ Am $J$ Aquacult 65, $39-43$.

19. Geurden I, Radünz-Neto J \& Bergot P (1995) Essentiality of dietary phospholipids for carp (Cyprinus carpio L.) larvae. Aquaculture 131, 303-314.

20. Coutteau P, Geurden I, Camara MR, Bergot P \& Sorgeloos P (1997) Review on the dietary effects of phospholipids in fish and crustacean larviculture. Aquaculture 155, 149-164.

21. Cahu CL, Zambonino-Infante JLZ \& Barbosa V (2003) Effect of dietary phospholipid level and phospholipid: neutral lipid value on the development of sea bass (Dicentrarchus labrax) larvae fed a compound diet. Br J Nutr 90, 21-28.

22. Kanazawa A (1993) Essential phospholipids of fish and crustaceans. In Fish Nutrition in Practice, Les Colloques $\mathrm{nr}$ 61, pp. 519-530 [SJ Kaushik and P Luquet, editors]. Versailles, France: INRA Editions.

23. Geurden I, Charlon N, Marion D \& Bergot P (1997) Influence of purified soybean phospholipids on early development of carp (Cyprinus carpio L.). Aquacult Int 5, 137-149.

24. Geurden I, Marion D, Charlon N, Coutteau P \& Bergot P (1998) Comparison of different soybean phospholipidic fractions as dietary supplements for common carp, Cyprinus carpio, larvae. Aquaculture 161, 224-235.

25. Fontagné S, Geurden I, Escaffre AM \& Bergot P (1998) Histological changes induced by dietary phospholipids in intestine and liver of common carp (Cyprinus carpio) larvae. Aquaculture 161, 213-223.

26. Olsen RE, Myklebust R, Kaino T \& Ringo E (1999) Lipid digestibility and ultrastructural changes in the enterocytes of Arctic char Salvelinus alpinus L. fed linseed oil and soybean lecithin. Fish Physiol Biochem 21, 35-44.

27. Olsen RE, Dragnes BT, Myklebust R \& Ringø E (2003) Effect of soybean oil and soybean lecithin on intestinal lipid composition and lipid droplet accumulation of rainbow trout, Oncorhynchus mykiss Walbaum. Fish Pysiol Biochem 29, $181-192$.

28. Geurden I, Bergot P, Schwarz L \& Sorgeloos P (1998) Relationship between dietary phospholipid class composition and neutral lipid absorption in postlarval turbot. Fish Physiol Biochem 19, 217-228.

29. Hadas E, Koven W, Sklan D \& Tandler A (2003) The effect of dietary phosphatidylcholine on the assimilation and distribution of ingested free oleic acid $(18: 1 n-9)$ in gilthead seabream (Sparus aurata) larvae. Aquaculture 217, 577-588.

30. Choubert G, De La Noue J \& Luquet P (1982) Digestibility in fish: improved device for the automatic collection of faeces. Aquaculture 129, 185-189.

31. National Research Council (1993) Nutrient Requirements of Fish. Washington, DC: National Academy Press.
32. Bolin DW, King RP \& Klosterman EW (1952) A simplified method for the determination of chromic oxide $\left(\mathrm{Cr}_{2} \mathrm{O}_{3}\right)$ when used as an index substance. Science 116, 634-635.

33. Bergot P \& Flechon JC (1970) Forme et voie d'absorption intestinale des acides gras à chaine longue chez la truite arc-en-ciel (Salmo gairdneri Rich.) I. Lipides en particles. Ann Biol Anim Biochim Biophys 10, 459-472.

34. Sire MF, Lutton C \& Vernier JM (1981) New views on intestinal absorption of lipids in teleostean fishes: an ultrastructural and biochemical study in the rainbow trout. J Lipid Res 22, $81-94$.

35. Iijima N, Aida S, Mankura M \& Kayama M (1990) Intestinal absorption and plasma transport of dietary triglyceride and phosphatidylcholine in the carp (Cyprinus carpio). Comp Biochem Physiol 96A, 45-55.

36. Oxley A, Torstensen BE, Rustan AC \& Olsen RE (2005) Enzyme activities of intestinal triacylglycerol and phosphatidylcholine biosynthesis in Atlantic salmon (Salmo salar L.). Comp Biochem Physiol 141B, 77-87.

37. Caballero MJ, Gallardo G, Robaina L, Montero D, Fernandez A \& Izquierdo M (2006) Vegetable lipid sources affect in vitro biosynthesis of triacylglycerols and phospholipids in the intestine of sea bream (Sparus aurata). Br J Nutr 95, 448-454.

38. Wallaert C \& Babin PJ (1994) Effects of temperature variations on dietary lipid absorption and plasma lipoprotein concentrations in trout (Oncorhynchus mykiss). Comp Biochem Physiol 109B, 473-487.

39. Werner A, Havinga R, Perton F, Kuipers F \& Verkade HJ (2006) Lymphatic chylomicron size is inversely related to biliary phospholipid secretion in mice. Am J Physiol Gastrointest Liver Physiol 290, G1177-G1185.

40. Noaillac-Depeyre J \& Gas N (1974) Fat absorption by the enterocytes of the carp. Cell Tissue Res 155, 353-365.

41. Babin PJ \& Vernier JM (1989) Plasma lipoproteins in fish. J Lipid Res 30, 467-490.

42. Fainaru M, Schafer Z, Gavish D, Harel A \& Schwarz M (1988) Interactions between human and carp (Cyprinus carpio) low density lipoproteins (LDL) and LDL receptors. Comp Biochem Physiol 91B, 331-338.

43. Skinner ER \& Rogie A (1978) The isolation and partial characterization of the serum lipoproteins and apolipoproteins of the rainbow trout. Biochem J 173, 507-520.

44. Chapman MJ, Goldstein S, Mills GL \& Leger C (1978) Distribution and characterization of the serum lipoproteins and their apoproteins in the rainbow trout (Salmo gairdnerii). Biochemistry 17, 4455-4464.

45. Ando S \& Mori Y (1993) Characteristics of serum lipoprotein features associated with lipid levels of muscle and liver from five species of fish. Bull Jpn Soc Sci Fisheries 59, 1565-1571.

46. Mansbach CMII (1977) The origin of chylomicron phosphatidylcholine in the rat. J Clin Invest 60, 411-420.

47. Goto T, Holzinger F, Hagey LR, Cerre C, Ton-Nu HT, Schteingart CD, Steinbach JH, Shneider BL \& Hofmann AR (2003) Physicochemical and physiological properties of 5 alpha-cyprinol sulfate, the toxic bile salt of cyprinid fish. J Lipid Res $\mathbf{4 4}$, 1643-1651.

48. De Smet H, Blust R \& Moens L (1998) Absence of albumin in the plasma of common carp Cyprinus carpio: binding of fatty acids to high density lipoprotein. Fish Physiol Biochem 19, 71-81. 